\title{
Original Article \\ Hairy cell leukemia: Clinical, pathological and ultrastructural findings in Asian-Indians
}

\author{
Chatterjee T, Panigrahi I, Mahapatra M, Pati HP, Kumar R, Naithani R, Wadhwa S, \\ Choudhry VP, Saxena R \\ Department of Hematology, AlIMS, Ansari Nagar, New Delhi-110 029, India.
}

Correspondence to: Dr. Inusha Panigrahi, E-mail: inupan@yahoo.com

\begin{abstract}
BACKGROUND: Hairy-cell leukemia (HCL), lymphoproliferative disease of older age, is characterized by projections from surface of abnormal cells. AIM: The aim was to study the clinical presentation and ultrastructural changes in hairy cells (HCs) following cladribine treatment. SETTINGS AND DESIGN: Clinical presentation, peripheral smear, bone marrow aspiration and biopsy of $\mathrm{HCL}$ cases diagnosed over a period of three years were reviewed. MATERIALS AND METHODS: Consecutive HCL cases in Hematology clinic of a tertiary care center were enrolled. Tartarate-resistant acid phosphatase (TRAP) test was done to detect HCs and electron microscopy was done to demonstrate initial ultrastructural changes and alterations following cladribine therapy. RESULTS: Fifteen cases of HCL, aged 32-57 years (median 47 years) were studied. The clinical presentation included splenomegaly in $15(100 \%)$, fever in $10(67 \%)$, hepatomegaly and pain abdomen in eight $(53 \%)$, fatigue in nine $(60 \%)$ cases. The commonest laboratory features were monocytopenia in $13(87 \%)$, neutropenia in $12(80 \%)$, anemia in $10(67 \%)$ and pancytopenia in nine $(60 \%)$. All patients showed symptomatic improvement on cladribine therapy. Electron microscopy after treatment (three months) showed loss of the finger like projections, characteristic bald lymphocytes, loss of ribosomal lamellar complexes, as well as decrease in mitochondria and vacuoles. CONCLUSIONS: Indian patients with $\mathrm{HCL}$ are younger. Cladribine is an effective therapy for these patients and leads to complete response in most of the patients. There is a significant improvement in the ultrastructural features following cladribine therapy.
\end{abstract}

Key words: Cladribine, complete response, lymphoproliferative disorder, purine analogs, TRAP test, ultrastructural features

\section{Introduction}

$\mathrm{H}$ airy cell leukemia $(\mathrm{HCL})$ is an indolent, chronic B-cell lymphoproliferative disorder comprising approximately 2 to $3 \%$ of all adult leukemias. ${ }^{[1]}$ It occurs more frequently in men ( $R$ atio 4:1) and mean age at diagnosis is approximately 52 years. It is primarily a disease of Caucasians. ${ }^{[2]}$ This series of patients aims at providing an evaluation of clinical presentation, with special emphasis on electron microscopic findings on cladribine therapy.

\section{Materials and Methods}

All $\mathrm{HCL}$ cases diagnosed in the $\mathrm{H}$ ematology department from D ecember 2001 to January 2004 were evaluated. A histological diagnosis of $\mathrm{HCL}$ was done with tartarate-resistant acid phosphatase (TRAP)-positive hairy cells in the peripheral blood or bone marrow. ${ }^{[3]}$ All these patients underwent complete blood counts, liver function tests, renal function tests and skiagram of chest. Clinical details, peripheral blood findings, bone marrow aspirate and biopsies and electron microscopy were reviewed. Bone marrow aspiration was performed by Salah needle and biopsy performed by modified Jenson needle from posterior superior iliac spine. PS and BMA smears were stained by Giemsa stain. Bone marrow biopsy was fixed in formalin, decalcified by formal citrate and stained by hematoxylin and eosin. Cellularity was based on visual examination and graded into three groups; normocellular (30-50\% of intertrabecular spaces occupied by hematopoietic cells), hypercellular (>50\%) and hypocellular $(<30 \%)$. For electron microscopy [LIBRA ${ }^{\circledR}$ Energy Filtering Transmission Electron Microscopes (EFTEM), Carl Zeiss International], bone marrow aspirates and/or peripheral blood were collected in 2-3 drops of preservative free heparin and processed 
using standard methods. U Itrathin sections double stained with uranyl acetate and lead citrate.

All the pts were treated with 2-chlorodeoxyadenosine (2-CdA) Cladrim (2-chloro-deoxy adenosine; D abur Pharma Ltd, Chennai) at a dose of $0.09 \mathrm{mg} / \mathrm{kg} / \mathrm{d}$ continuous iv infusion for seven days; with pump, using a PICC. Complete response (CR) was defined as absence of hairy cells in bone marrow aspirates and biopsy at three and six months after cessation of therapy as well as cessation of symptoms related to pancytopenia as well as normalization of counts of all three cell lineages along with normalization of splenic size. Partial response (PR) meant presence of hairy cells in excess of $5 \%$ in aspirates with partial response in spleen size and symptoms.

\section{Results}

There were 15 cases (10 M: 5F) of hairy cell leukemia ( $\mathrm{HCL}$ ), with a median age 47 years (range 32-57 years). Median duration of symptoms was eight months (range 6-14 months). Table 1 shows the fraction of patients presenting with various clinical manifestations.

A nemia of a variable degree was present in $66 \%$ with median haemoglobin $(\mathrm{H} \mathrm{b}$ ) of $8.6 \mathrm{~g} \%$ (range of 5-12 $\mathrm{g} / \mathrm{dl})$. Median total leucocyte count was

\section{Table 1: Clinical presentation and laboratory characteristics in 15 cases of hairy cell leukemia}

\begin{tabular}{lclc}
\hline Clinical features & No. (\%) & Lab findings & No. (\%) \\
\hline Fatigue & $9(60)$ & Anemia & $10(67 \%)$ \\
\hline Pallor & $9(60)$ & Thrombocytopenia & $9(60)$ \\
\hline Fever & $10(67)$ & Neutropenia & $12(80)$ \\
\hline Weight loss & $5(33)$ & Monocytopenia & $13(87 \%)$ \\
\hline Bleeding/ecchymosis & 2 & Bicytopenia & $4(27 \%)$ \\
\hline Palpable purpura & 1 & Pancytopenia & $9(60)$ \\
\hline Arthralgia/pain abd & $8(53)$ & Leukocytosis & 1 \\
\hline Abdominal Discomfort & 4 & Hairy cells in PS & $15(100)$ \\
\hline Splenomegaly & $15(100)$ & Hairy cells in BM & $15(100)$ \\
\hline Hepatomegaly & $8(53)$ & TRAP positive & $14(93 \%)$ \\
\hline Lymphadenopathy & 2 & BM cellularity normal & $9(60)$ \\
\hline Infection & $4(27 \%)$ & BM cellularity & increased \\
\hline & & High LAP score & $8(53)$ \\
\hline & & HCL Classical & $14(93)$ \\
\hline & HCL Variant & 1 \\
\hline
\end{tabular}

$3000 / \mathrm{mm}^{3}$ (range $800-17,400$ ) and mean platelet count was $66000 / \mathrm{mm}^{3}$ (range $30000-120000 / \mathrm{mm}^{3}$ ). $\mathrm{N}$ eutropenia was the commonest presentation (80\%) with pancytopenia being present in $60 \%$ cases. Table 1 shows the laboratory parameters of the patients.

There were 14 classical and 1 variant $\mathrm{HCL}$. Bone marrow biopsy was available in all cases. Biopsy was normocellular in $8 / 15$ (53\%) and hypercellular in $7 / 15$ (47\%) cases. Table 2 shows the immunophenotype of the patients. I mmunohistochemistry was all-negative in 1 case. DBA 44 was positive in two cases where it was done. Immunophenotypic and electron microscopic findings are listed in Table 2.

Symptomatic improvement was seen in all patients on cladribine therapy. Eighty percent of patients obtained a CR (12 patients) remainder showed PR (3) post treatment ( 3 months). The three patients with PR were re-administered 2-chlorodeoxyadenosine (2-CdA) $0.1 \mathrm{mg} / \mathrm{kg} / \mathrm{d}$ (cladribine) continuous iv infusion for another seven days; They showed complete response. Electron microscopy showed loss of the finger-like projections, as characteristic bald lymphocytes as well as loss of ribosomal lamellar complexes in all cases, which initially showed presence of these complexes. There was significant reduction in the number of mitochondria as well as vacuoles. Follow-up of all 15 patients is being done now at six-monthly interval and as on date (threeyear follow-up) all are doing well with normal counts, absence of spleen and cessation of symptoms.

\section{Discussion}

$\mathrm{HCL}$ is a rare malignant disorder of the elderly. The median age at diagnosis reported is usually around 52 years. In a French study, 30 cases of HCL were diagnosed over a 25-year period; the median age was 67.8 years. ${ }^{[2]}$ The median age in our series of 15 patients was 47 years, which is relatively younger. The predominant manifestions in present study were splenomegaly, fever and cytopenias. Splenomegaly was the commonest feature $(100 \%)$, fever and monocytopenia were also common. H owever, anemia was present in a significant proportion of cases (67\%). In a study from HongKong in $18 \mathrm{HCL}$ cases; fever, splenomegaly and monocytopenia were the predominant manifestations ${ }^{[4]}$ and $14 / 18$ were alive at six-year followup. Earlier reports in Indian patients are limited. ${ }^{[5-7]}$

The bone marrow biopsy has become an additional tool for assessment of prognostic factors. Increasing cellularity has been associated with worse survival. In present study, we found normal cellularity in 53\% while in $47 \%$ cases it was increased. Pattern of BM involvement in 
Chatterjee $\mathrm{T}$, et al.: Cladribine and ultrastructural changes in $\mathrm{HCL}$

$\begin{aligned} & \text { Table 2: The results of immunophenotyping and transmission electron microscopy in the hairy cell } \\
& \text { leukemia cases }(\mathbf{n = 1 5})\end{aligned}$
\begin{tabular}{lll} 
Marker No. $(\%)$ & TEM features No. $(\%)$ \\
\hline CD $11 \mathrm{C} 12(80 \%)$ & Vacuoles and vesicles (frequent) $10(67 \%)$ & $\begin{array}{l}\text { Single nuclear profile with } 1 \text { or } \\
\text { more indentations } 10(67 \%)\end{array}$ \\
CD $2511(73 \%)$ & Mitochondria (numerous) $15(100 \%)$ & Numerous fine microvilli $10(67 \%)$ \\
\hline CD $10313(87 \%)$ & Ribosomal lamellar complexes $9(60 \%)$ & Broad based microvilli $5(33 \%)$ \\
\hline CD $1914(93 \%)$ & Perinuclear fibrils $5(33 \%)$ & Short strands of rough ER $9(60 \%)$ \\
\hline Smg $15(100 \%)$ & Nucleoli 2 & Moderate-well developed golgi body $5(33 \%)$ \\
\hline FMC $710(67 \%)$ &
\end{tabular}

$\mathrm{HCL}$ is pathognomic. Classically 'diffuse honeycomb' appearance with nucleus of each HC surrounded by halo of cytoplasm (fried egg pattern) is seen.

NAP score was elevated in eight patients of $\mathrm{HCL}$ in present series, regardless of the presence or absence of infection. With response to therapy, NAP score falls, but it rises after treatment is discontinued. NAP score parallels the hairy cell index.

TRAP enzyme concentrates primarily in Golgi area and nuclear membrane. ${ }^{[8]}$ TRAP and DBA 44 expression are specific for hairy cell leukemia. ${ }^{[9]}$ A combined DBA $44 /$ TRAP positivity was seen in only $3 \%$ of non-HCL non-H odgkin lymphomas. In the present study we could pick up 14/15 (93\%) cases by the TRAP test. Immunophenotyping is very useful in diagnosis of $\mathrm{HCL}$. It differentiates $\mathrm{HCL}$ from its variants and other $\mathrm{B}$ cell malignancies. The CD 19 and Smg positivity was seen in $14 / 15(93 \%)$ and $15 / 15(100 \%)$ respectively in present study. $\mathrm{H}$ airy cells can be detected by flowcytometry in peripheral blood of $92 \%$ of patients, even if the hairy cells are $<1 \%$ of the lymphocytes. Specificity and sensitivity to diagnose $\mathrm{HCL}$ by immunohistochemistry is increased when DBA 44 is used in conjunction with $9 \mathrm{C} 5 \mathrm{Ab}$ and anti CD20 Ab.

Electron microscopy helped us to confirm diagnosis in one TRAP negative patient, expressing typical cytoplasmic projections. U Itrastructurally the projections are elongated and slender microvilli or broad based ruffles or pseudopods are present. Frequent vacuoles, vesicles and numerous mitochondria are seen. Ribosomal lamellar (RL) complexes (50\% cases) appear as rodshaped structure under light microscopic analysis. Most of these findings were present in our patients. $R L$ complexes are also seen in other chronic B cell lymphoproliferative disorders, acute monocytic leukemias and even non-hematologic neoplasms. The HCL variant makes up $10 \%$ of all $\mathrm{HCL}$ cases, as was a case in present series (1/15). It differs from typical $\mathrm{HCL}$ in patients being older (median age 71 years, TLC $>50 \times 10^{9} / \mathrm{L}$ ) and the hairy cells may/may not be TRAP positive. $\mathrm{H}$ airy cells show high $\mathrm{N} C$ ratio, more condensed chromatin and prominent nucleoli.

M itochondrial abnormalities have been seen in different cancers. Since the mitochondrial membrane potentials in cancer cells are frequently reduced in comparison with those of non-neoplastic cells this allows small molecule agents to enter the tumor cell mitochondria and reduce oxygen consumption with activation of a caspase pathway to apoptosis which is cancer cell specific. Thus targeted cancer therapy can be tried by increasing mitochondrially mediated apoptosis. The anticancer drug prodigiosin (PG) acts via mitochondrial pathway. ${ }^{[10]}$ Quantification of plasma mitochondrial nucleic acids may be used to recognize patients with a poor prognosis in advanced prostate cancer. ${ }^{[11]} M$ any colorectal cancers harbor mtD N A mutations that are associated with poor prognosis. ${ }^{[12]}$ The mitochondrial abnormalities including the number and type of mitochondria can be detected by electron microscopy and it is an important research tool. In the present study, there was decrease in number of mitochondria following treatment.

Treatment of $\mathrm{HCL}$ is indicated in patients with significant neutropenia, anemia, thrombocytopenia, symptomatic splenomegaly, constitutional symptoms or recurrent serious infections. ${ }^{[1]}$ M ost patients in present study responded to cladribine therapy. Previous studies from Mumbai have shown responses to alpha-interferon therapy. ${ }^{[4,5]}$ Pai et al, ${ }^{[6]}$ found an overall response of $88.9 \%$ and disease free survival of $83 \%$ on interferon therapy. Survivals at 5 and 10 years were $34.4 \%$ and $29.6 \%$ respectively for untreated patients, $58.8 \%$ and $44.1 \%$ for patients receiving chemotherapy, steroids or other drugs, $64.1 \%$ and $56.1 \%$ for splenectomized patients and $88.9 \%$ (at 5 years) for alpha interferon (IFN)-treated patients in an Italian study. ${ }^{[13]} \mathrm{H}$ owever, a single dose of cladribine induces a long-term CR. O ver 
$90 \%$ of patients are alive 13 years later and over $50 \%$ of patients appear to be clinically cured by this treatment in an Italian study. ${ }^{[14]}$ The overall survival (OS) at 12 years after start of cladribine therapy was $79 \%$ in German patients. ${ }^{[15]}$ The efficacy of cladribine treatment in present study is reflected in loss of the finger like projections and $\mathrm{RL}$ complexes, along with decrease in the mitochondria and vacuoles. Interferon treatment leads to shorter projections, disappearance of RLCS; and appearance of tubuloreticular structures (TRS) and cylindrical confronting cisternae (CCC) in $2.2 \%$ and $6.8 \%$ of the cells. ${ }^{[16,17]}$ Addition of monoclonal antibodies may lead to better responses in $\mathrm{HCL}$ patients. ${ }^{[18]}$ Strategies for therapy in relapsed disease include retreatment with purine analog, rituximab or the anti-CD 22 pseudomonas exotoxin A immunoconjugate, BL-22. ${ }^{[19]}$ In Indian cases with HCL in present study, $3 / 15$ patients with partial response showed a complete response after a repeat course of cladribine. L ong-term follow-up of up to 14 years (median: 9.7 years) in a study from USA showed an excellent progression free survival and OS after 2-CdA treatment. ${ }^{[20]}$ In the present series also, all 15 patients are doing well with no progression of symptoms at three years follow-up.

The cost of cladribine treatment is around 80,000 to one lakh for a $70 \mathrm{~kg}$ adult as one vial $(10 \mathrm{mg})$ costs around Rs. 11,000. Additional costs include the cost of infusion sets, overall around Rs. 1.5 lakh. In contrast the cost of the drug only for alfa-interferon (Roferon-A/ Alferon) treatment over 6 months is Rs. 1.5 lakh. Thus, cladribine is a better and cheaper treatment for $\mathrm{HCL}$ in Indians.

\section{Acknowledgments}

We thank the staff at the electron microscopy facility of the institute for their help in the EM studies.

\section{References}

1. Goodman GR, Bethel KJ, Saven A. Hairy cell leukemia: An update. Curr Opin Hematol 2003; 10:258-66.

2. Malfuson JV, Gisserot O, Cremades S, Doghmi K, Fagot T, Souleau $\mathrm{B}$, et al. Hairy-cell leukemia: 30 cases and a review of the literature. Ann Med Interne (Paris) 2003; 154:435-40.

3. Yam LT, Janckila AJ, Li CY, Lam WK. Cytochemistry of tartrateresistant acid phosphatase: 15 years' experience. Leukemia $1987 ; 1: 285-8$.
4. Au WY, Kwong YL, Ma SK, Mak YK, Wong KF, Lei KI, et al. Hairy cell leukemia in Hong Kong Chinese: A 12-year retrospective survey. Hematol Oncol 2000;18:155-9.

5. Malhotra H, Advani SH, Gopal R, Saikia TK, Nadkarni KS, Pai VR, et al. Alpha-interferon in hairy cell leukemia: An initial Indian experience. J Assoc Physicians India 1992;40:159-61.

6. Pai S, Shinde SC, Saikia TK, Gopal R, Nair CN, Advani SH. Hairy cell leukemia-results with alpha interferon therapy. J Assoc Physicians India 1999;47:605-7.

7. Spiers AS, Parekh SJ. The treatment of hairy cell leukemia with 2'deoxycoformycin: results in India and in the United States. Leukemia 1987:1:347-50.

8. Drexler HG, Gignac SM. Characterization and expression of tartrateresistant acid phosphatase (TRAP) in hematopoietic cells. Leukemia 1994;8:359-68

9. Went PT, Zimpfer A, Pehrs AC, Sabattini E, Pileri SA, Maurer R, et al. High Specificity of Combined TRAP and DBA.44 Expression for Hairy Cell Leukemia. Am J Surg Pathol 2005;29:474-8.

10. Soto-Cerrato V, Llagostera E, Montaner B, Scheffer GL, Perez Tomas R. Mitochondria-mediated apoptosis operating irrespective of multidrug resistance in breast cancer cells by the anticancer agent prodigiosin. Biochem Pharmacol 2004;68:1345-52.

11. Mehra N, Penning M, Maas J, van Daal N, Giles RH, Voest EE. Circulating mitochondrial nucleic acids have prognostic value for survival in patients with advanced prostate cancer. Clin Cancer Res 2007; 13:421-6.

12. Chen D, Yu Z, Zhu Z, Lopez CD. The p53 pathway promotes efficient mitochondrial DNA base excision repair in colorectal cancer cells. Cancer Res 2006;66:3485-94.

13. Frassoldati A, Lamparelli T, Federico M, Annino L, Capnist G, Pagnucco G, et al. Hairy cell leukemia: A clinical review based on 725 cases of the Italian Cooperative Group (ICGHCL). Italian Cooperative Group for Hairy Cell Leukemia. Leuk Lymph 1994;13:307-16.

14. Zinzani PA, Tani M, Marchi E, Stefoni V, Alinari L, Musuraca G, et al. Long-term follow-up of front-line treatment of hairy cell leukemia with 2-chlorodeoxyadenosine. Haematologica 2004;89:309-13.

15. Jehn U, Bartl R, Dietzfelbinger H, Haferlach T, Heinemann V. An update: 12-year follow-up of patients with hairy cell leukemia following treatment with 2-chlorodeoxyadenosine. Leukemia 2004; 18: 1476-81.

16. Morroni M, Ripa G, Bolognesi G, Leoni P, Cinti S. Ultrastructural modifications in one case of hairy cell leukemia during alpha-interferon therapy. Tumori 1992;78:190-7.

17. Mantovani G, Astara G, Curreli L, Lai P, Turnu E, Locci F, et al. Ultrastructural, immunologic and clinical follow-up of five patients with $\mathrm{HCL}$ treated with interferon (IFN) for more than three years. Haematologica 1992;77:326-35.

18. Else M, Ruchlemer R, Osuji N, Del Giudice I, Matutes E, Goodman A, et al. Long remissions in hairy cell leukemia with purine analogs: $A$ report of 219 patients with a median follow-up of 12.5 years. Cancer 2005; 104:2442-8.

19. Tallman MS, Zakarija A. Hairy cell leukemia: survival and relapse. Long-term follow-up of purine analog-based therapy and approach for relapsed disease. Transfus Apher Sci 2005;32:99-103.

20. Chadha P, Rademaker AW, Mendiratta P, Kim B, Evanchuk DM, Hakimian D, et al. Treatment of hairy cell leukemia with 2-chlorodeoxyadenosine (2-CdA): Long-term follow-up of the Northwestern University experience. Blood 2005; 106:241.

Source of Support: Nil, Conflict of Interest: None declared. 